the ward (who, with considerable courage, had locked himself into the ward with the patient) was physically attacked, and subsequently escaped serious injury by the narrowest of margins when a plate glass observation panel was shattered around him by a heavy vase thrown at him as he was telephoning for help. Had this patient not been tackled, he would have run amuck amongst the visitors who were just cntaring the building. The third incident concern:d a paranoid schizophrenic who, on being brought from an ambulance into an admission ward, fought vigorously with the nursing staff under the delusional belief that they were his persecutors.

Such patients need to be restrained both for their own safety and for the safety of others (and in order that psychotropic drugs may be given), but there are times when this can only be achieved with a struggle. To believe otherwise is to blind oneself to the reality of psychotic behaviour. If four or five staff members are involved there is virtually no risk of anyone being hurt, but if only one or two are coping with the outburst then the degree of force they will need to exert, both to control the patient and, at times, to defend themselves will be much greater. Complaints of manhandling and ill-use will be made-understandably so, perhaps, from the psychotic point of view of the patient; but not to control the situation would leave the staff and the hospital open to severe criticism if damage were to be caused by the aggressive behaviour of the patient. It is not so long ago that a young boy was murdered a few yards outside my hospital by a schizophrenic who was not restrained.

The recent publicity given to incidents and conditions in certain hospitals dealing with psychiatric patients serves to underline the fact, surely known to us all, that in any corporate body there will be black sheep, try as one may to detect and eradicate them before damage is done. The loyalty, kindness, and patience of the vast majority of psychiatric nurses-working under adverse if not intolerable conditions for a wage which any right-minded person knows to be a scandal-are something we tend to take for granted. Scant publicity is ever given to this, and in the public mind the one nurse who falls short overshadows the hundreds who do the exact opposite.

It seems right, Sir, to state publicly the medical profession's indebtedness to our nursing colleagues, without whom we in the hospital service would be totally unable to function. One wonders if we do all that we could to draw public attention to the invaluable and quite irreplaceable service rendered to us and-more importantly-to our patients by them.-I am, etc.,

Highcroft Hospital

D. Anton-Stephens.

\section{Cancer and Mitochondrial D.N.A.}

SIR,-The letter from Professor G. F. Gause (16 August, p. 413) on the use of mutant micro-organisms in the study of cancer cell mitochondria prompts me to make the following comments. There is certainly experimental evidence ${ }^{l}$ that the mitochondria in the cells of higher organisms may have evolved from endosymbiotic bacteria. How- ever, the function of the genetic "message" coded by the sequence of bases in mitochondrial D.N.A. has not yet been fully elucidated, and is expected to be substantially different. Indeed, Küntzel ${ }^{2}$ has produced figures which make it unlikely that there is sufficient mitochondrial D.N.A. to code for the R.N.A. of the mitochondrial ribosomes as well as the various structural and functional proteins, in order to render the mitochondrion independent. Furthermore, it would appear ${ }^{2-4}$ that not all mitochondrial proteins, structural and functional, are synthesized on mitochondrial ribosomes. It will prove a considerable task to determine which protein(s) may be affected by mutation of the mitochondrial D.N.A. and then to interpret their significance to mitochondrial function. Also the degree of autonomy and the mechanism of replication of these cytoplasmic organelles are not settled, so one can further speculate on the effect of abnormal mitochondria on the normal remainder in the same cell. This latter complexity can only be taken properly into account with mammalian systems, and not with those recommended by Professor Gause.

A study of the malignant cell based on a comparison between mutant micro-organisms and the organelles of the much more elaborate mammalian cell seems somewhat restricted. Indeed, if one assumes the correctness of the " triplet" code of bases for the amino-acids, it is remarkable that mutants with such an altered base composition as Professor Gause has reported ${ }^{3}$ can synthesize proteins at all.

This criticism in no way condemns the unicellular experimental systems that Professor Gause describes, which could provide valuable and fundamental information about the biological activity of the mitochondrion. Rather it is to be hoped that effort and resources in cancer research will continue to be expended on studies with mammalian systems, such as that by Clayton and Vinograd ${ }^{6}$ on normal and leukaemic human leucocytes, which may lead to an understanding of the significance of the abnormal mitochondrion in the cancer cell.-I am, etc.,

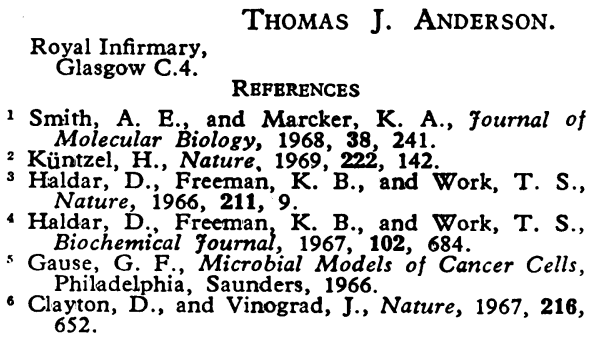

\section{Adhesions and Fibrosis}

SIR, - I was very interested to read $\mathrm{Mr}$. E. C. Ashby's contention (9 August, p. 350) that intra-abdominal adhesions may be found more often in people in whom there is a fibrotic diathesis. While I am sure that such a diathesis does exist, my own recent experience in Nairobi does not exactly comply with Mr. Ashby's hypothesis.

Laparotomy on the native population of Kenya resulted in many hypertrophic abdominal scars, but I was not aware of a particularly high incidence of subsequent adhesion obstruction. It is well known that the coloured races tend to produce hyper- trophic scars and keloids more readily, but in the matter of duodenal ulceration, for example, which is now becoming more prevalent in Nairobi, excessive scarring and fibrosis were not found. What was striking was the fact that the African patient healed so well as he did, when many conditions were of ten unfavourable-for example, marked anaemia and malnutrition.

I appreciate this raises wider issues not strictly relevant here. However, the only obvious or apparent local factor was the relative'y high vitamin-C content of the East African diet. Despite a recent pronouncement to the contrary, ${ }^{1}$ it is generally assumed that the average diet in developed countries is not lacking in vitamin $\mathbf{C}$ and there is, of course, much work to support the influence of vitamin $C$ in healing. ${ }^{2}$ It is also well recognized that certain areas of the body are more prone to produce gross scarring-for example, the shoulder, or over the sternum." So, while we may agree that a fibrotic diathesis does exist in some patients, the responsible factors are far from obvious, and are probably multiple.-I am, etc.,

\section{Stobhill General Hospital Glasgow N.1. \\ REFERENCES \\ Pauling, Second International Congress of Social Psychiatry, 1969 . London.
Ross, R., and Benditt, E. P., fournal of Cell Bio- logy, 1964, 22, 365 . Africa, 1968. ' Edinburgh, Livingstone.
avey, W. W. Companion to Surgery in}

\section{Liver Function and the Pill}

SIR,-I was interested that Dr. J. Clinch and Mr. V. R. Tindall (8 March, p. 602) found the rates of transfer of bromsulphalein (B.S.P.) to be modified in puerperal women who took stilboestrol in order to suppress lactation. Using the biphasic elimination of B.S.P. from the blood, described by Richards, ${ }^{12}$ they were able to demonstrate the toxic effect of the stilboestrol on liver cells, possibly owing to the blocking of intracellular enzymes.

However, it is difficult to accept from their graphs that the first part of the curve is similar for all three groups of puerperal women, because it is represented by only 2 points at 3 and 10 minutes, whereas the second part is represented by 11 points. In the absence of other biological evidence, and especially of chromatographic studies of B.S.P.'s metabolites and bile acid levels in the blood, there is insufficient evidence to justify the conclusion of an enzymatic block within the liver cells.

In my own experience the peripheral disappearance curve is made up of more than two phases and exponents, probably owing to the metabolites of the B.S.P. regurgitating into the blood. Moreover, I have rarely been able to diagnose the first slope as normal and the second one as pathological. My impression is that the first slope is better related to the clinical picture.

If one studies the biliary elimination of B.S.P. by the technique described by Caroli and Tanasoglu ${ }^{3}$ (continuous aspiration of the duodenal juice) and the ${ }^{131}$ I-Rose Bengal by measuring the radioactivity in the umbilical area, one can both detect early damage of the liver cells and the early cholestatic 